of the original pebble. The operator had first broken the pebble into two halves, and then chipped two-thirds of one half away in flakes, of which I found thirteen; the remainder of that half he threw down as useless. Of the other half I have nine flakes, and one is missing; the unbroken remainder is also gone. Perhaps the workman threw it away to a distance in disgust, as he does not seem to have got a single satisfactory flake out of the whole flint. The appearance of the half which I have almost complete is extremely like the illustration of the core made up out of a modern flint-knapper's flakes in Evans' "Stone Implement," except that the crowns of the flakes are triangular instead of quadrangular. There are the same small interstices between the crowns of the flakes, showing that the blow splinters off on each side of the bulb of percussion a small fragment, as well as the flake itself. This explains why the average concavity on the core is slightly less than the average convexity of the flake at the top of the bulb of percussion.

Crosby, Liverpool

\section{Climate of Atacama}

SOME practical evidence as to climate has come forward at the shareholders' meetings of the northern Railways of Chile, the Coquimbo, Tongoy, and Carrizal and Cerro Blanco. In each of these districts torrential rains have occurred, which are all reported as unexampled. Long residents state that rain was formerly little known, and such was my observation in connection with the district. One reason why the weather is deserving of attention is that no change has taken place in the water-surface or vegetation. A similar change to rain in the Suez and Cairo district is attributed to the Suez Canal, but it is a matter worthy of consideration whether we are not really entering on a cycle of change. So far as Atacama is concerned, if at any former period there were rains, the conditions of habitation must have been different from those which have been so long considered to apply to the rainless district.

HYDE CLARKE

Phylloxera Congress.-Dr. E. R. F. wishes to know where he can obtain a full report of the recent Phylloxera Congress at Bordeaux.

SCientific Instruments (J. S. Marston).-We cannot undertake to commend any particular instrument maker; you should get the lists of the leading makers, whose addresses you will find in our advertising columns.

Holloway College.-So far as we understand this is not a charitable institution: Miss S. should write to the authorities at the College, Staines.

Effects of Coloured Glass (E. M.).--It is owing to the law you refer to.

\section{THE AUTUMN SKY}

\section{I.}

MANY and varied must ever be the regrets that attend 1 the departure of summer days and summer pleasures; and their remembrance casts a lingering sadness even over the bright and beautiful hours that often alleviate the approach of sterner and gloomier seasons. Such impressions however are not shared alike by all. Few perhaps altogether escape their influence; but in some classes they are softened or even obliterated by the development of interests and pleasures of a very different description. Such is especially the case with the astronomical observer. The shortening of the twilight hours is to him as the withdrawing of a veil that obscured the minuter, yet not least interesting, features of the glorious scenes that he loves to explore; and he views with fresh pleasure the deepening tone of the background of unfathomable space, as the atmospheric illumination fades steadily away. We cannot indeed in our latitudes rival the transparent purity of the south, that gives such a magnificent depth to the aspect of the firmament, and throws out in such radiant brilliancy the host of heaven; yet even our autumnal skies are so great an advance upon the misty softness of the summer's night that the observer cannot but rejoice in their return.

These remarks are very obvious, not to say somewhat late in their application, when the sun has already ad vanced so far upon his downward way: yet they may not be entirely inappropriate when we are about to draw attention to some of the present characteristics of the sky. Much now in every direction invites the inquiring gaze, and an early hour challenges the opening of the observatory, or the arrangement of the telescope. Eyepieces should be cleaned, adjustments rectified. Instruments of all kinds and sizes may be called into profitable and pleasant requisition-let the possessors only make the best of what they have. If we do not see more than we anticipate, though that may sometimes happen among the uncertainties of the English climate, yet we shall surely see enough to amaze us at the greatness of the Creator.

From its pre-eminent brightness, the planet Jupiter will naturally be the first object of attention. Belts we shall expect to find traversing his great broad disk, for they are very seldom absent; but there also we shall encounter a more unusual object, the ruddy patch, which has been sometimes described as vermilion, possibly from "personal equation," but which to most eyes exhibits a cinnamon or brick-red hue. There it has been, with scarcely any appreciable change, for the last three years ${ }^{2}$ - a degree of permanence equalled, and even surpassed, by some dark spots in ancient days, but singularly contrasted with the general mutability of the markings of the disk. What is that spot? and where is it situated with regard to the real surface of the planet? Is it mere superficial colouring? but if so, of what material? Or is it an opening in the great mass of clouds-or what we call such-that is thought to envelope this colossal globe? But if so, how strange that its outline should have remained so steadily permanent. And in that case, as it is difficult to suppose it at the same level with those dark grey bands which have been ascribed to a similar absence of vapour, shall we place it above or bel uw them? We might infer the former, if it is the case, as has been said, that it is more easily traced up to the limb than the dark belts; but the observation is delicate, and the effacing of the grey bands in that situation is not matter of universal consent. We might possibly conceive, on other grounds, admitting that the dark belts do indicate a deep clearing of vapour, that ruddy tints are caused by something at a higher level, because these are occasionally suffused over the whole equatorial zone and its markings, so as sometimes even to affect the general colour of the planet to the naked eye. The interposition of trees has prevented the writer hitherto from observation this year, but the accompanying sketch, taken 1879, November I2, with my $9 \frac{1}{3}$-inch

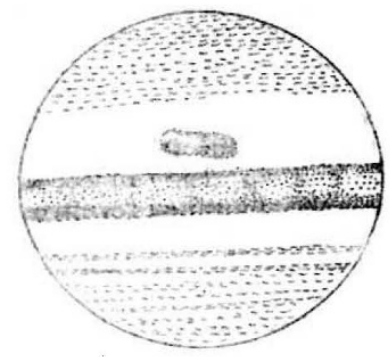

FIG. I.

"With" mirror, may perhaps be of some interest in comparison with the observations of the present season.

The image, it will be noted, is telescopic, i.e. inverted.

I Traces 0 ? it may be detected in the Earl of Rosse"s observations in $x^{8} 7_{3}$; but it seems to have been unnoticed in the interval. 
The red spot was suspected to consist of two confluent masses, as well as to be somewhat inclined to the neighbouring belt; but the former idea, at least, not being confirmed by other observers, was probably owing to the inferior atmospheric conditions, which did not admit of a power much above 10o. The central girdle consisted as usual of three divisions: the $\mathrm{N}$. broadest and darkest, and of a cinnamon hue ; the equatorial zone pale grey, with very feeble transverse interruptions, an indistinct continuation of the "portholes" so conspicuous some years previous; the $\mathrm{S}$. band grey also, but deeper in tone. The $\mathrm{N}$. hemisphere, beyond a bright region, had many faint grey stripes : towards the opposite pole was a feeble brownish shading; so that the colouring of the disk as a whole was, in heraldic language, "counterchanged." On other occasions very singular tints have been noted by eminent observers-yellow, full blue, and crimson; and the subject well deserves study, even though, as seems likely, that study should lead to little of a satisfactory nature.

Then there are other markings to be investigated on that great disk, both luminous and dusky, and that in another aspect, with a view to the determination of rotation; for, strange to say, it is found that some small dark specks travel more rapidly than other bright ones, and that the red spot moves slowest of all. And thus it is that the uncertainty in the axial velocity of that vast globe, first noticed by Cassini more than two centuries ago, is almost as far from being removed as ever; and, on the whole, one is tempted to question whether, after all, we have a single accurate idea, excepting that of mutability, concerning that enormous surface; and whether, if we could be transported there, we should not be surprised at the baselessness of all our conjectures. Certainly it may be said as to Jupiter, and not as to Jupiter only, that the recent advances in optical power and observing skill have only served to make more evident the thickness of the veil that obscures these objects in mystery. Analogy leads us a little way safely enough, but only to desert us before long. However, we must patiently watch and wonder.

Other matters, too, might be noted before we take our leave of that brilliant disk, so easy of investigation, so difficult to interpret. Why are the shadows cast on it by the satellites sometimes so black, at others so dim, or so abnormally small? Why, when a satellite passes behind the limb, is it sometimes neatly bisected by it, at others visible behind or through it, either from optical projection, as stars have been seen in front of the moon, or from the partial transparency of the edge of the globe? And then the satellites-they, too, have their anomalies in differences of apparent magnitude and brightness, due perhaps to variable obscurations of surface, but, if so, indicating conditions totally unlike that of our own satellite-the presence of considerable atmospheres, the possible want of coincidence between their periods of revolution and rotation-or even a superficial constitution as mutable and as hard of interpretation as that of the primary whom they obey.

We shall not remove our telescope far before a still more interesting and surprising object will present itself in Saturn, now especially suited for investigation, both as to altitude and the presentation of the ring. If there was much in Jupiter to perplex us, there is far more here; and it is rather mortifying to remark how little advance in knowledge has been made by the great increase, in recent years, of telescopic power. But little is ascertained now, beyond what was detected by the perfect vision of Dawes with his $6 \frac{1}{3}$-inch Merz object-glass, or the beautiful definition of the 15 -inch achromatic, by the same maker, at Harvard College. A study, in fact, of the memoir by Bond and his associates, in the Annals of that college, vol. ii. part I, published in 1857 , would be the best preparation for an intelligent scrutiny of this planet. But not much beyond a general impression can be expected from ordinary telescopes. It will require considerable power, as well as light and sharpness, to detect Encke's subdivision of the outer ring (which, however, I caught in 1880 with my $9 \frac{1}{3}$-inch mirror), to trace any possible subdivisions of the inner ring, to ascertain whether, as Trouvelot thinks, the gauze veil is becoming less transparent in its outer portion, or to investigate those strange and puzzling outlines of the shadow of the ball on the rings, which, noted in part by others, have been recorded in detail in the Harvard memoir. A copy is here given of one, but not perhaps the most remarkable, of their diagrams.

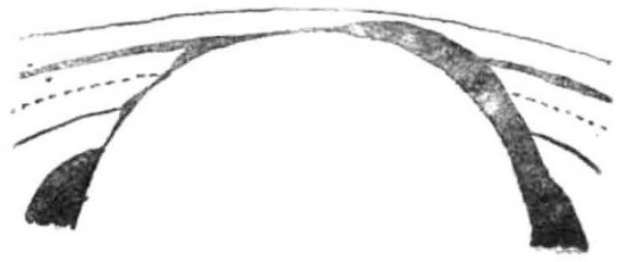

F1G. 2.

Such a contour could be only accounted for, if at all, by an amount of unequal thickness in the ring, which ought to be, but is not in the smallest degree, visible in the edgeways presentation. The success of Prof. Hall in detecting a bright spot of considerable permanency upon the ball encourages attention in that directionespecially as there are several previous records of such phenomena. To hunt for the smaller satellites with any but superior instruments would of course be waste of time, but it may be remarked that Enceladus has been seen by Ward with exceptionally keen sight and a 4.3 inch Wray object-glass, by Franks with 5 inch ditto, by Pratt with an 8.15 inch "With" mirror, and by myself with 9:33 inch. Mimas, the innermost, has been detected with a 7-inch achromatic by Wray. Meyer at Geneva has found it of late nearly as bright as Enceladus, and thinks it may be variable.

The morning skies at present are graced by Venus, not however a remarkable object in her gibbous phase; and Mars, who is coming rapidly round by his opposition to the evening. The smallness of his diameter, about $15^{\prime \prime}$, is a great impediment, especially in the English sky, to the hope of success with his minor details, though it may be borne in mind that in the air of Milan, and with an admirably defining Merz object-glass of $7 \frac{1}{7}$ inches, Schiaparelii has made many delicate observations on a scarcely larger diameter, and with exceptionally fine air has carried them down, strange as it may appear, to a diameter of only $6^{\prime \prime}$.

The only other of the larger planets now visible is Neptune, easily picked up by means of an ephemeris, and distinguishable from a fixed star, even in a small telescope, by its dull and steady light. It demands, however, a large aperture for the bringing out and sharp definition of its pallid disk; in the latter respect the great achromatics at Rome ( $9^{\circ} 3$ inch) and Bothkamp ( I I 5 inch) were unsuccessful, but I have seen it neatly terminated with Huggins's I 5 -inch object-glass. Its satellite, though glimpsed by Ward with a 43 -inch achromatic, is far too difficult for ordinary vision or common apertures; I have seen it however plainly with the I5inch just mentioned.

Vesta, though possibly visible with the naked eye, is a mere brilliant point of less than $I^{\prime \prime}$ in the telescope.

Some notes on the autumnal constellations will be brought forward in a subsequent paper.

(To be continued.) 